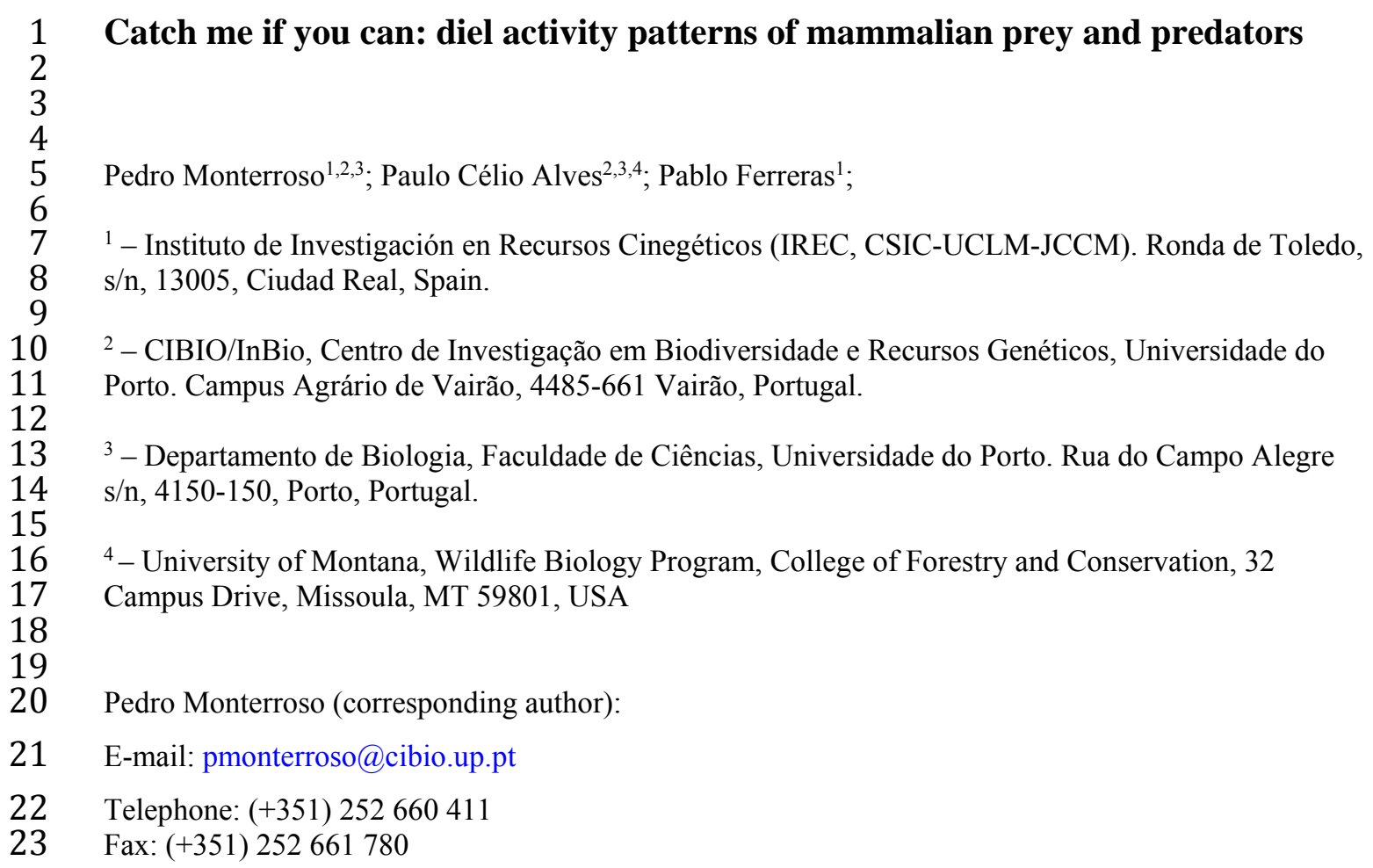

\section{Catch me if you can: diel activity patterns of mammalian prey and predators}

Pedro Monterroso ${ }^{1,2,3}$; Paulo Célio Alves ${ }^{2,3,4}$; Pablo Ferreras ${ }^{1}$;

1 - Instituto de Investigación en Recursos Cinegéticos (IREC, CSIC-UCLM-JCCM). Ronda de Toledo, s/n, 13005, Ciudad Real, Spain.

2 - CIBIO/InBio, Centro de Investigação em Biodiversidade e Recursos Genéticos, Universidade do Porto. Campus Agrário de Vairão, 4485-661 Vairão, Portugal.

3 - Departamento de Biologia, Faculdade de Ciências, Universidade do Porto. Rua do Campo Alegre s/n, 4150-150, Porto, Portugal.

${ }^{4}$ - University of Montana, Wildlife Biology Program, College of Forestry and Conservation, 32 Campus Drive, Missoula, MT 59801, USA

Pedro Monterroso (corresponding author):

21 E-mail: pmonterroso@cibio.up.pt

22 Telephone: $(+351) 252660411$

23 Fax: (+351) 252661780

Paulo Célio Alves - E-mail: pcalves@fc.up.pt

26 Pablo Ferreras - E-mail: pablo.ferreras@uclm.es

28 Running title: Diel activity patterns of mammalian prey and predators

29 Words in the text (including the title, references and figure legends): 7876

34 We adhere to the 'Guidelines for the use of animals in research' as published in Animal Behaviour

35 (1991, 41, 183-186) and the laws of the countries where the research was conducted.

36 The manuscript contains only material that is either original and has not been published or submitted 37 elsewhere, or stems from publications identified by a reference.

38 All authors have seen the final manuscript and take responsibility for its contents. 
41 The activity patterns exhibited by animals are shaped by evolution, but additionally fine-tuned by

42 flexible responses to the environment. Predation risk and resource availability are environmental cues

43 which influence the behavioral decisions that make both predators and prey engage in activity bursts,

44 and depending on their local importance, can be strong enough to override the endogenous regulation

45 of an animals' circadian clock. In Southern Europe, wherever the European rabbit (Oryctolagus

46 cuniculus) is abundant, it is the main prey of most mammalian mesopredators, and rodents are

47 generally the alternative prey. We evaluated the bidirectional relation between the diel activity

48 strategies of these mammalian mesopredators and prey coexisting in Southwestern Europe. Results

49 revealed that even though predation risk enforced by mammalian mesocarnivores during nighttime was

50 approximately twice and five times higher than during twilight and daytime respectively, murids

51 consistently displayed unimodal nocturnal behavior. Conversely, the European rabbits exhibited a

52 bimodal pattern that peaked around sunrise and sunset. Despite the existence of some overlap between

53 the diel rhythms of mesocarnivores and rabbits, their patterns were not synchronized. We suggest that

54 the environmental stressors in our study areas are not severe enough to override the endogenous

55 regulation of the circadian cycle in murids. European rabbits, however, are able to suppress their

56 biological tendency for nocturnality by selecting a predominantly crepuscular pattern. In spite of the

57 higher energetic input, mesocarnivores do not completely track rabbits' activity pattern. They rather

58 track rodents' activity. We propose that these systems have probably evolved towards a situation where

59 some degree of activity during high-risk periods benefits the overall population survival.

60

61 Keywords: Diel activity; Predation risk; Optimal foraging; Mesocarnivores, Southwestern Europe 


\section{Introduction}

66 The fundamental ecological niche refers to the full range of conditions (biotic and abiotic) and resources in which an organism can survive and reproduce (Elton 2001). However, local environmental pressures such as inter-specific relations act on individuals narrowing the breadth of utilization of at least one of the niche dimensions or resources, promoting the co-existence (Hutchinson 1957). Time can be regarded as a niche dimension over which interacting animals might segregate to reduce the

71 effect of agonistic encounters (Carothers \& Jaksić 1984). The nycthemeral or diel activity patterns are 72 the most evident and best studied in animal ecology (Halle \& Stenseth 2000) and, according to Halle 73 (2000), consist of "adaptative sequences of daily routines that meet the time structure of the 74 environment, shaped by evolution, but additionally fine-tuned by flexible responses to the actual state of the environment". This means that the daily activity of an animal is intrinsically constrained, and therefore its plasticity for local adaptation is fairly limited (Schoener 1974; Kronfeld-Schor \& Dayan 2003). For instance, nocturnal mammals have developed anatomical and physiological characteristics adapted to dim light activity such as effective camouflage, large inner ears and movable auricles, or eyes with large lens in relation to the focal length and large corneas (Ashby 1972; Bartness \& Albers 2000). Conversely, an animal adapted to diurnal activity would be exceptionally vulnerable and grossly unsuccessful in nighttime foraging (DeCoursey 2004). Animals without an endogenous specialization to strictly diurnal or nocturnal rhythms are fairly effective over the entire diel cycle, and therefore increase the possibilities for local circadian adaptation. However, they will not be perfectly adapted to

84 either phase (Halle 2000). In this context, each animal will try to explore the temporal niche dimension to maximize energetic gain and other biological needs, while reducing individual costs, e.g. mortality risk (Brown et al. 1999; Halle 2000; DeCoursey 2004). In predator-prey systems continuous arms race take place over the spatial and temporal dimensions

88 (Eriksen et al. 2011). Along the latter, a simplistic way of viewing this system is that prey struggle to 89 reduce predation risk by reducing activity overlap with predators, while the latter track down prey by 90 trying to synchronize their activity with them, in a constant and dynamic relation (Lima 2002).

91 Consequently, we would expect that the diel activity pattern of a given prey species in a particular 92 location to be the result of its evolutionary physiological adaptations (i.e. fundamental niche) and the selective pressures exerted locally such as predation pressure, accessibility to resources and intra-guild 

shaped by the same evolutionary processes and local constraints, but with an additional limitation imposed by temporally available feeding resources (i.e. prey; Halle 2000; Lima 2002). However, the predator's specialization on a given prey, and both preferred and alternative prey availabilities also play an important role in the structure of the daily activity pattern. A specialist predator, which is evolutionarily bound to its staple prey, should more avidly try to synchronize its rhythm with it.

100 Conversely, a more generalist species should only track a given prey so far, especially if alternative

101 feeding resources are available with minor costs.

102 In Southern Europe small mammals (mainly rodents) and the European rabbit (Oryctolagus cuniculus)

103 are the most profitable prey for mammalian mesocarnivores (Malo et al. 2004; Lozano et al. 2006;

104 Delibes-Mateos et al. 2008b). In fact, rodents are consumed with considerable frequency by most

105 European mesocarnivore species, especially in the Atlantic ecoregion (Lozano et al. 2006; Zhou et al.

106 2011; Díaz-Ruiz et al. 2013). However, the energetic trade-off between predation costs and individual

107 prey intake favours the predation upon European rabbit wherever it reaches moderate to high

108 abundance (Malo et al. 2004). Hence, the European rabbit assumes a particularly important role in the

109 Mediterranean ecosystems' functioning, being the preferred prey of a variety of predators (Delibes \&

110 Hiraldo 1981; Delibes-Mateos et al. 2008a).

111 We investigate the temporal strategies of mammalian prey (small mammals and European rabbits) as a

112 response to diel structure of predation risk imposed by mammalian mesocarnivores. For a better

113 understanding of the dynamic organization of this predator-prey system, the diel pattern of

114 mesocarnivore-mediated predation risk is also investigated as a response to prey diel activity,

115 availability and community structure. Our predictions were that 1) in the Atlantic ecoregion, where

116 rabbits are very scarce, a high overlap and synchrony between rodents and mammalian mesopredators

117 should indicate a dominant strategy within the predator community to maximize access to small

118 mammals; 2) In Mediterranean ecoregion, the mammalian mesopredator community should track the

119 activity of European rabbits in detriment of small mammals, whenever the lagomorph is abundant.

\section{Methods}

122

a. Study areas 
123 Activity data was collected in four different study sites of the Iberian Peninsula (Fig. 1): two in

124 Portugal, the Guadiana Valley Natural Park (GVNP) and the Peneda-Gerês National Park (PGNP); and

125 two in Spain, the Cabañeros National Park (CNP) and the Muniellos Natural Reserve (MNR). Two of

126 these study sites (GVNP and CNP) are located in the Mediterranean region of the Iberian Peninsula,

127 and have a Mediterranean pluviseasonal continental bioclimate (Rivas-Martínez et al. 2004). Scrubland

128 patches are mainly associated with steeper slopes, elevation ridges and main water bodies, and are

129 dominated by Pyro-Quercetum rotundifoliae and Myrto communis-Querco rotundifoliae series and

130 other subserial stages (Rivas-Martínez 1981; Costa et al. 1998). Areas with gentler slopes are mainly

131 occupied by cereal crops and a savannah-like system, with holm oak trees (Quercus rotundifolia)

132 scattered within a grassland matrix (García-Canseco 1997).

133 The PGNP and MNR are located in the Atlantic region of the Iberian Peninsula, and have a temperate

134 oceanic submediterranean bioclimate (Rivas-Martínez et al. 2004). The landscapes consist of

135 mountainous agricultural-forest mosaic, where mountain tops are mostly dominated by scrublands with

136 Ericaceae, Ulex sp. and Betulaceae habitats, and mountain slopes and valleys are essentially dominated

137 by oligotrophic oak forests (dominated by Quercus sp., Betula and Fagus sp.). Pastures, agricultural

138 fields and small villages are found scattered through the landscape, mainly along valleys and lower

139 altitude locations (UNESCO; Prieto \& Sánchez 1996; Carvalho \& Gomes 2004).

140 A study area of approximately 6000 ha within each of the study sites was selected, based on criteria of

141 ecosystem conservation status and logistic factors.

144 All study areas were sampled in two seasons: Autumn (Jul-Oct), when the offspring of most medium-

145 sized carnivores from that year become independent; and Spring (Feb-Apr), during these species'

146 breeding season (Blanco 1998).

147 Field sampling was based on camera-trapping of both carnivore mesopredators and their mammalian

148 prey. The spatial sampling scheme and camera-trap sites' selection followed the procedures described

149 by Monterroso et al. (2011). In summary, between 32 and 41 cameras were uniformly spaced in each

150 study area following a grid-sampling scheme, composed by $1 \mathrm{~km}^{2}$ squares. Camera traps were placed on

151 every other vertex of the grid squares, resulting in a sampling grid of $\sim 1.4 \mathrm{~km}$ (which corresponds to

152 the distance between diagonal grid nodes). Two camera-trap models were used: Leaf River IR5 
153 (LeafRiver OutDoor Products, Taylorsville, Mississippi, USA) and ScoutGuard (HCO OutDoor

154 Products, Norcross, Georgia, USA). Cameras were mounted on trees approximately $0.5-1.0 \mathrm{~m}$ off the

155 ground and set to record time and date when triggered. We programmed cameras with the minimum

156 time delay between consecutive photos to maximize the number of photos taken per captured

157 individual. Camera traps were maintained in the field for a minimum period of 28 days and were

158 inspected for battery or card replacement every 7 to 14 days. A combination of carnivore attractants

159 was used in order to incite animals' curiosity and thus increase detection probabilities. The attractants

160 used were Lynx urine, obtained from captive specimens of Eurasian lynx (Lynx lynx) and Iberian lynx

161 (Lynx pardinus), and Valerian extract solution, as suggested by Monterroso et al. (2011) for Iberian

162 carnivore sampling. Attractants were placed in the field at a distance of 2-3 $\mathrm{m}$ from the camera traps,

163 and were deployed in perforated separated plastic containers, at a distance of $10-15 \mathrm{~cm}$ from each other

164 and approximately $30 \mathrm{~cm}$ above the ground. Five to $10 \mathrm{~mL}$ of each attractant were sprayed into a cotton

165 gaze, held inside each container. Attractants were re-baited every 7 to 14 days. When multiple

166 photographs of the same species were taken within a 30-minute interval we considered them as a single

167 capture event to ensure capture independence (unless animals were clearly individually distinguishable;

168 Kelly \& Holub 2008; Davis et al. 2011).

c. Prey abundance

171 European rabbits' relative abundance was estimated using pellet counts, which has been argued as the

172 indirect method that provides the most reliable estimates (Palomares 2001; Fernández-de-Simón et al.

173 2011). Fourteen to fifteen (mean \pm standard error: $14.5 \pm 0.3$ ) grids were sampled in each study area.

174 Each sampling grid consisted of 9 to 12 (mean \pm standard error: $10.5 \pm 0.9)$ sampling plots, regularly

175 spaced at $15 \mathrm{~m}$ intervals. Each sampling plot consisted of a circular $0.5 \mathrm{~m}^{2}$ area, which was cleared of all

176 rabbit pellets at the beginning of each sampling campaign. Sampling plots were then recounted after

$17718.7 \pm 0.4$ (mean \pm standard error) days post-clearing. Rabbit relative abundance was assessed as an

178 uncorrected daily pellet accumulation rate (UNC), which was obtained by calculating the average

179 number of pellets per square meter divided by the number of days elapsed since the initial cleaning

180 (Fernández-de-Simón et al. 2011). Sampling grids location in each study area followed criteria of

181 accessibility and proportional spatial representativity of the most relevant habitats. 
182 The relative abundance of murids (Apodemus sp. and Mus sp.) was assessed by the means of live

183 captures. Using the same sampling grids and plots' placement previously described, nine live traps

$184(5.1 \times 6.4 \times 16.5 \mathrm{~cm}, \mathrm{SFG}$ folding traps, H.B. Sherman traps, Tallahassee, FL, USA) were set for the

185 capture of small mammals. In the study areas located in the Atlantic ecoregion (PGNP and MNR), an

186 extra line of three larger sized live traps $(7.6 \times 8.9 \times 22.9 \mathrm{~cm}$, LFG folding traps, H.B. Sherman traps,

187 Tallahassee, FL, USA) was set at each sampling grid because of the expected higher abundance of

188 voles (Microtus sp. and Arvicola sp.). A trapping campaign consisted of three consecutive trapping

189 days. Traps were monitored after sunrise, to reduce stress in captured animals. All captured individuals

190 were then identified to the species level, sexed, weighted and aged without the resort to any kind of

191 chemical immobilization. Each captured animal was marked with a small hair cut in the right hind leg,

192 to ensure that recaptures could be adequately identified. After handling, each animal was released at the

193 capture site. A relative abundance index was calculated as the number of new individuals captured 100

194 trapping-days ${ }^{-1}$ (Watkins et al. 2009).

\section{d. Statistical analyses}

197 The independent detection records for each species were regarded as a random sample from the 198 underlying continuous temporal distribution that describes the probability of a photograph being taken 199 within any particular interval of the day (Ridout \& Linkie 2009). The probability density function of 200 this distribution (i.e. activity pattern; Linkie \& Ridout 2011) was estimated nonparametrically using 201 kernel density estimates following the procedures described by Ridout \& Linkie (2009). Following the 202 estimation of the distribution function, pairwise comparisons of activity patterns between mammalian 203 predators and prey species were performed by estimating the coefficient of overlap $\Delta_{1}$, as suggested by 204 Ridout \& Linkie (2009) and Linkie \& Ridout (2011) for small sample sizes whenever the number of records was $<50$ detections. The coefficient of overlap $\Delta_{4}$ was used when sample size was $\geq 50$

206 detections. The coefficient of overlap ranges from 0 (no overlap) to 1 (complete overlap), and is

207 obtained taking the minimum of the density functions of the two species or species complexes (e.g. all 208 mesocarnivores) being compared at each time point. The precision of this estimator was obtained 209 through confidence intervals, as percentile intervals from 500 bootstrap samples (Linkie \& Ridout 210 2011). Target species consisted of all carnivore species with mean body weight between 1.0 and $7.0 \mathrm{~kg}$ 211 detected in the study areas: red fox (Vulpes vulpes); European wildcat (Felis silvestris); pine marten 
213 genetta); and Egyptian mongoose (Herpestes ichneumon). In order to evaluate the potential effect of

214 mesocarnivore-mediated predation risk on prey activity rhythm, all carnivore data were also pooled

215 together and subjected to the same analysis.

216 The reliability of kernel estimates was assessed using non-negative trigonometric sum distributions

217 (Fernández-Durán 2004), which were also fitted to the same detection data. As estimates based on the

218 trigonometric sums and kernel densities should be broadly similar (Ridout \& Linkie 2009), whenever

219 estimates' difference was $\geq 0.2$, we assumed that they were imprecise and were, therefore, discarded.

220 Whereas the coefficient of overlap might provide useful information on the probability of two species

221 being active at a given period of the day, alternative measures focusing on the degree of synchrony of

222 peaks of activity may also be of ecological interest (Ridout \& Linkie 2009). Therefore, Pearson

223 correlations were estimated to evaluate the level of synchrony between prey and predator, using kernel

224 probability estimates for 512 equally spaced time points along the day, i.e. a point at approximately

225 each $2.8 \mathrm{~min}$.

226 All statistic analyses were performed using R software (R Development Core Team 2008). The R code

227 used to estimate overlap coeficients was adapted from that provided by Ridout \& Linkie (2009).

228 Nighttime, daytime and twilight (defined as the period enclosed between one hour prior to one hour

229 after sunrise and sunset, Lucherini et al. 2009) durations can vary between seasons and study areas, and

230 are also different among them within the $24 \mathrm{~h}$ day cycle. Therefore, we calculated a "density of

231 detections" where the total number of independent detections in each of defined periods was divided by

232 the duration (in hours) of that period per 100 trap-days. The data on predator activity was interpreted as

233 a predation risk proxy for each period of the day, as we assume that the density of detections relates to

234 the probability of prey species encountering a mesocarnivore predator at a given time of the day. Data

235 are presented as mean \pm standard error, unless explicitly stated.

\section{Results}

238 A total of 8346 trap-nights (1043 \pm 47 trapping days ${ }^{*}$ campaign $\left.^{-1}\right)$ were obtained from all study sites and seasons. A total of 4911 independent detections were obtained, of which 1309 were mesocarnivores

$240\left(164 \pm 52\right.$ detections $\cdot$ campaign $\left.^{-1}\right), 758$ were small mammals $\left(95 \pm 20\right.$ detections $\cdot$ campaign $\left.^{-1}\right)$ and 2844

241 were European rabbits ( $356 \pm 233$ detections $\cdot$ campaign $\left.^{-1}\right)$. 
Small mammals activity patterns and abundance

244 Murid rodents where detected across all study areas and seasons (table 2). They consistently revealed nocturnal activity with a tendency for the onset to occur just after sunset and cessation just before sunrise (figure 2). Activity density functions suggest a unimodal pattern, occasionally with a slight reduction of activity between $01 \mathrm{~h} 00$ and $04 \mathrm{~h} 00$ (figure 2). The density of detections was always higher

248 during nighttime $\left(0.84 \pm 0.17\right.$ detections hour ${ }^{-1} 100$ trapping days $\left.^{-1}\right)$, followed by twilight $(0.13 \pm 0.04$ detections hour ${ }^{-1} 100$ trapping days $^{-1}$ ). Daytime detections were rare (only one detection obtained

250 during daytime, at CNP during Autumn season).

251 Muridae species revealed similar abundance indexes in the Atlantic $(6.00 \pm 1.83$ new captures 100

252 trapping days $\left.{ }^{-1}\right)$ and Mediterranean $\left(5.18 \pm 0.80\right.$ new captures $\cdot 100$ trapping days $\left.{ }^{-1}\right)$ study areas

253 (Kruskal-Wallis test, $\mathrm{H}=0.02, \mathrm{p}=0.88$ ). However, species compositions varied between ecoregions: In

254 Mediterranean areas $58 \%$ of all captured individuals were Algerian mice (Mus spretus), while in

255 Atlantic areas 97\% of captures consisted of either wood or yellow-necked mouse (Apodemus sylvaticus 256 and A. flavicollis).

\section{European rabbit activity patterns and abundance}

259 European rabbits were mostly detected in the Mediterranean study areas $(\mathrm{N}=2844)$. Only two rabbit 260 detections were obtained from the Atlantic region, both from the PGNP in Autumn season (table 1).

261 Activity was recorded at all hours of the day, but activity density functions revealed a strong bimodal 262 activity pattern, with a major activity peak occurring at sunrise and throughout the morning. A second 263 activity peak took place in late afternoon, dropping after sunset (figure 3).

264 Activity was more intense during twilight hours $\left(3.23 \pm 2.22\right.$ detections hour ${ }^{-1} 100$ trapping days $\left.^{-1}\right)$.

265 The intensity of activity recorded during nighttime and daytime was of $1.29 \pm 0.91$ and $1.40 \pm 0.93$

266 detections hour ${ }^{-1} 100$ trapping days $^{-1}$, respectively.

267 The European rabbit, when detected, revealed only residual abundances in the study areas from the 268 Atlantic region (table 2). In the Mediterranean study areas, this lagomorph was over 10 times more 269 abundant at GVNP $\left(174.9 \pm 31.5\right.$ pellets $\cdot 100$ days $\left.^{-1} \cdot \mathrm{m}^{-2}\right)$ than in $\mathrm{CNP}\left(11.5 \pm 5.1\right.$ pellets $\cdot 100$ days $^{-1} \cdot \mathrm{m}^{-}$ $\left.270{ }^{2}\right)$. 
273 Independent carnivore detections were obtained in 1309 occasions across all study areas and seasons,

$27458.4 \%$ of which belonged to red fox $(\mathrm{N}=750$, table 1 , figure 4$)$. The pine marten, stone marten and common genet were detected in $158(12.3 \%), 107$ (8.3\%) and 104 (8.1\%) occasions. The European

276 wildcat accounted for 76 detections (5.9\%) and the Eurasian badger and Egyptian mongoose for 44

$277 \quad(3.4 \%)$ and $46(3.7 \%)$ detections, respectively.

278 The proportional contribution of each species to the mesocarnivore detection data varied across sites and seasons (figure 4). The pine marten was only detected in study areas in the Atlantic region, while

280 the Egyptian mongoose was only detected in the Mediterranean ones (figure 4, table 4). The remaining

281 species had variable individual contributions across study areas and seasons.

282 Predation risk imposed by mammalian mesocarnivores revealed a consistent tendency to be higher during nighttime, although with variable degrees of diurnal intensity (figures 2 and 3). Concordantly,

284 nighttime was the period that accounted for more density of detections $\left(1.06 \pm 0.27\right.$ detections hour $^{-1}$ 100 trapping days $\left.{ }^{-1}\right)$, followed by twilight $\left(0.61 \pm 0.19\right.$ detections hour $^{-1} 100$ trapping days $\left.^{-1}\right)$ and daytime $\left(0.26 \pm 0.12\right.$ detections hour ${ }^{-1} 100$ trapping days $\left.{ }^{-1}\right)$. Daytime activity in the Mediterranean areas was mostly due to red fox and Egyptian mongoose activities, which accounted for $71 \%$ and $25 \%$ of all diurnal detections in this region, respectively. The high proportion of red fox detections was responsible for the observed daytime activity of mesocarnivore community at CNP (table 3), while at

290 GVNP, daytime activity was mainly due to the activity of Egyptian mongooses, which contributed with

$29180 \%$ of all daytime detections. In the Atlantic ecoregion, daytime activity was only detected in three 292 species: the red fox, the European wildcat and the pine marten

293 Considering detection rates, the chances of a prey species encountering a mesocarnivore during the 294 night would be, on average, $1.9 \pm 0.2$ greater than during twilight and $5.2 \pm 0.8$ times greater than during daytime. Likewise, the chances of encounters with these predators during the twilight are, on 296 average, $2.9 \pm 0.4$ times greater than during daytime. The rank of predation risk during these periods of 297 the daily cycle was consistent across all study areas and seasons.

Predator and prey activity overlap and synchrony

300 The coefficient of overlap estimates obtained from $\Delta_{1}$ and $\Delta_{4}$ produced very similar results for study areas and seasons (mean difference $=0.017 \pm 0.002$ ). Therefore, the results will be reported only for $\Delta_{4}$. 
302 The mesocarnivore community revealed a diel activity pattern, which widely overlaps with the one

303 observed for small mammals in all study areas and seasons. Mean coefficient of overlap ranged from

3040.60 to 0.89 (table 4). High synchrony was also observed between mesocarnivore species and small

305 mammals' activities, as mean Pearson correlation ranged from 0.74 to 0.94 (table 5).

306 The coefficient of overlap between mesocarnivore activity and small mammals was similar in

307 Mediterranean and Atlantic areas $(0.73 \pm 0.05$ vs. $0.78 \pm 0.04$; Kruskal-Wallis test, $\mathrm{H}=0.53, \mathrm{p}=0.47)$.

308 Activity synchrony values revealed the same pattern ( $0.85 \pm 0.05$ vs. $0.87 \pm 0.04$; Kruskal-Wallis test,

$309 \mathrm{H}=0.00, \mathrm{p}=1.00)$. Concordantly, in Mediterranean areas, where enough data on European rabbits

310 allowed for an adequate evaluation of activity patterns, almost significant differences were observed

311 between the coefficients of overlap among the mesocarnivore community and the lagomorph, and

312 between the mesocarnivore community and small mammals $(0.52 \pm 0.08$ vs. $0.73 \pm 0.05$; Kruskal-

313 Wallis test, $\mathrm{H}=3.00, \mathrm{p}=0.08$ ). Moreover, significant differences exist between the same pairs with

314 respect to synchrony of activity $(0.85 \pm 0.05$ vs. $-0.20 \pm 0.23$; Kruskal-Wallis test, $\mathrm{H}=5.30, \mathrm{p}=0.02)$,

315 suggesting that despite the existence of some overlap in the diel rhythms of rabbits and their

316 mammalian predators, the former tend to intensify their activity at dawn and dusk (figure 3), when

317 predation risk is lower (tables 4 and 5).

\section{Discussion}

320 Activity rhythms of small mammals

321 The rodent communities present in our study areas appear to be mostly composed by wood, yellow-

322 necked and Algerian mice, all muridae species which revealed to be nearly exclusively nocturnal.

323 Generally, the onset of activity followed sunset, whereas offset preceded sunrise. Very few records of

324 small mammal activity were collected after sunrise and before sunset, and only three $(\approx 0.4 \%)$ were

325 obtained in plain daytime. These results are consistent with findings of Roll et al. (2006) who, after a

326 revision of the activity patterns of 1150 species of rodents, concluded that phylogeny constrains

327 species' activity patterns, and muridae are nocturnal species. However, the rigidness of the underlying

328 endogenous circadian clock may be masked on an ecological timescale through the effect of

329 adaptations to local environmental challenges, such as predation risk (Jedrzejewska \& Jedrzejewski

330 1990; Halle 2000; Kronfeld-Schor \& Dayan 2008). The Algerian mouse in the Iberian Peninsula has

331 been described as mainly nocturnal except in winter, when it is multiphasic (Palomo et al. 2009). 
332 Similarly, the wood mouse has been described as predominantly nocturnal (Wolton 1983), even though

333 some diurnal activity has also occasionally been registered (Flowerdew 2000). Voles (Microtus sp. and

334 Arvicola sp.) however, have been reported to have more adaptable daily rhythms, displaying diurnal,

335 crepuscular or nocturnal activity patterns in response to environmental cues (Jacob \& Brown 2000;

336 Roll et al. 2006; Kronfeld-Schor \& Dayan 2008). Nevertheless, the comparatively low density and

337 detection of these species compared to that of wood and Algerian mice preclude them from having a

338 pronounced effect in the overall diel activity structure of the rodents' assemblage, which exhibited

339 marked nocturnality.

340 The diel pattern of predation risk imposed by mammalian mesocarnivores varies between the different

341 ecoregions and study areas (table 3). However, predation risk does not come from only one group of

342 predators (mammalian carnivores, considered in this paper), but rather from a joint effect of several

343 predator assemblages (e.g., also diurnal and nocturnal raptors; Halle, 2000), which also vary between

344 areas. In spite of these differences, the nocturnality of murid rodents in the Iberian Peninsula was

345 consistent through study areas, suggesting that the environmental stressors found there are not severe

346 enough to override the endogenous regulation of the circadian cycle.

Activity rhythm of European rabbits

349 The diel activity pattern of European rabbits revealed a consistent crepuscularity in both Mediterranean

350 study areas, with a higher activity density at sunrise than at dusk (Villafuerte et al. 1993, Diez et al.

351 2005), especially in the Autumn season. Despite possessing the general characteristics of nocturnal

352 animals (Jilge \& Hudson 2001), the European rabbit enjoys a high plasticity, which allows it to display

353 a variety of diel activity structures (Moreno et al. 1996; Lombardi et al. 2003; Moseby et al. 2005). In

354 field conditions, Bakker et al. (2005) found that the temporal patterns of rabbit activity responded to

355 perceived predation risk, and rabbits increased daytime foraging and reduced nighttime activity when

356 perceived the presence of a nocturnal predator. In this sense, Fernandez-de-Simón et al. (2009)

357 suggested that spatial and temporal variations in crepuscular vs. nocturnal activity in the European

358 rabbit in central Spain are related to the relative abundance of nocturnal vs. diurnal predators (including

359 human hunters). The plasticity in the diel pattern of European rabbits grants them adaptative

360 advantages by being able to choose the activity period that reduces the probability of being predated.

361 Predominant crepuscular activity has been suggested as a strategy of prey species to avoid both diurnal 
and nocturnal predators (Halle 2000), and the twilight period probably provides the best survival probabilities for European rabbits where predation pressure is high both by diurnal predators, such as

364 avian raptors, and nocturnal mammalian carnivores. Our results revealed that predation risk by mesocarnivores is nearly twice during nighttime than during twilight. In spite of the lower predation risk by mammalian predators during daytime, diurnal raptors will most likely make this period of the day highly risky as both Mediterranean study areas harbour healthy populations of raptor predators (García-Canseco 1997; ICN 2006).

A downside of our analysis is that it evaluates the activity patterns of rabbits as if it was similar across the entire landscape (irrespective to habitat structure). Previous work has suggested both rabbits and rodents can locally adapt their spatial and temporal strategies as a response to perceived predation risk (Moreno et al. 1996; Villafuerte \& Moreno 1997; Fernández-de-Simón et al. 2009) in what has been described as "the ecology of fear" (Brown et al. 1999; Ripple \& Beschta 2004). These prey species tend become more gregarious when in riskier (open) microhabitats, and microhabitat dependent predation risk may also influence behavioural decisions (Pierce, Longland, \& Jenkins 1992; Villafuerte \& Moreno 1997; Ebensperger \& Wallem 2002). Therefore, within each study area, both rabbits' and murids' behavioural responses could change at a micro scale as an adjusted response to locally implemented predation risk. However, while microhabitat variables were not registered and our analyses failed in detecting these fine scale nuances of prey behaviour, we were able to characterize the circadian activity cycles that reflect the behavioural strategies of the studied populations as a whole??

\section{Activity rhythm of mesocarnivores and temporal structure of predation risk}

383 Our results revealed higher intensity of mesocarnivore activity at twilight and nighttime hours in both

384 ecoregions (figures 3 and 4). However, some diurnal activity occurred. While having anatomical adaptations for nighttime foraging (Wilson \& Mittermeier 2009), most mesocarnivores found in

386 European communities can also effectively forage during light hours, as supported by the detection of daytime activity in our work as well as in previous research (e.g. Germain et al. 2008; Kavanau \&

388 Ramos, 1975; Palomares \& Delibes 2000; Zalewski 2000). However, mesocarnivores have to cope 389 with the problem of variable prey availability, both at the spatial and temporal scales (Halle 2000; 390 Weckel et al. 2006), while also trying to avoid agonistic encounters with top-predators, intraguild competitors and humans (Palomares et al. 1995; Fedriani et al. 1999). This complex web of interactions 
influences the ultimate expression of the diel activity rhythms of this group, which should be locally adapted. The overall similar pattern observed across the study areas and seasons suggests either a strong evolutionary imprint of the diel activity in mesocarnivores or a similitude of environmental circumstances leading to parallel strategies.

Predator and prey activity overlap and synchrony

398 Optimal foraging theory predicts that an animal will display a foraging pattern that maximizes its caloric intake per time unit (MacArthur \& Pianka 1966; Pyke et al. 1977). Therefore, taking into account that most species found in European mesocarnivore communities require prey to be active in order to detect and capture them, we would expect mesocarnivore activity patterns to be close to that of

402 the most profitable available prey. Small mammals are the most preferred prey by European mesocarnivores in the Atlantic region (Virgós et al. 1999; Lozano et al. 2006; Zhou et al. 2011; Díaz-

404 Ruiz et al. 2013), while in the Mediterranean region, the European rabbit takes place as the most profitable prey because of its high energetic value (Malo et al. 2004). However, our results reveal a

406 high consistency in the synchrony and overlap between small mammals' and mesocarnivores' activity patterns, even in the Mediterranean study areas. In this region, where the European rabbit should

408 emerge as preferred prey, only moderate values of activity overlap and low values of synchrony were

409 found with mesocarnivores. The predation risk allocation hypothesis proposed by Lima \& Bednekoff

410 (1999) advocates that through a reasonably accurate perception of predation risk, prey species adapt

411 their activity strategies to avoid being active in high risk periods. By allocating strong antipredator

412 behaviours to such periods, they then compensate by focusing its feeding effort in low-risk situations.

413 This theory is supported by Fenn and MacDonald (1995) who found that brown rats (Rattus

414 norvegicus) shift their diel activity patterns when perceived predation risk by red foxes was removed.

415 Low-risk feeding efforts may be particularly intense when high-risk periods are long or frequent (Lima

416 \& Bednekoff 1999; Sih \& McCarthy 2002). This situation seems to apply to the case of the European

417 rabbit in the Mediterranean region. The strong bimodal pattern of the rabbits diel activity is coherent

418 with a strategy of antipredator behaviour during long periods of high predation risk, while an

419 intensification of the feeding efforts are concentrated in periods when predation pressure relaxes.

420 However, if we look at this system from the predators' point of view, if the European rabbit is such an 421 energetically profitable prey, why don't predators completely overlap European rabbits daily rhythms? 
422 The predator-prey temporal relations vary between two extremes: first, the prey species completely

423 manages to avoid predators by being active when they are not. This situation would obviously be

424 disadvantageous for the predators, which would loose important energetic intake, and probably reduce

425 their populations up to the level of local extinction (specialist predator species; Ferrer \& Negro 2004)

426 or to a point where predation risk would stop being significant for the prey population (Halle 2000). In

427 the other extreme, predators perfectly track prey in the temporal scale. In this case, predation success

428 would probably be excessively high, leading to the depletion of the feeding resource (Sinclair et al.

429 1998) or driving prey into a predator pit (Trout \& Tittensor 1989; Pech et al. 1992; Sinclair et al. 1998).

430 Neither of these antagonist cases is beneficial for any of the species in the long run. Thus, we suggest

431 that predators only track prey activity so far, reaching a point when the trade-off between predation

432 success and the energetic intake is sufficient to fulfil its biological needs. These systems have probably

433 evolved towards a balanced situation, where some degree of foraging activity during high-risk periods

434 benefits the overall population survival. This situation should hold for species that, like the European

435 rabbit, have a wide option of temporal selection (i.e. are able to forage at different periods of the day)

436 and that suffer from intensive stalking from predator species. Such a pattern was reported by Arias-Del

437 Razo et al. (2011) with coyotes (Canis latrans) and lagomorphs in Mexico. They found that both

438 predator and prey species exhibited bimodal diel activity, but only one of the activity peaks was

439 synchronized between them, meaning that there was a part of the day when prey chose to be active

440 when the predator was not. Similarly, Roth II \& Lima (2007) found that sharp-shinned hawks

441 (Accipiter striatus) and their preferred prey activities only partially overlapped, contradicting predator-

442 prey game theory (Kotler et al. 2002).

443 The strong evolutionary imprint that binds the murid species to nocturnal activity (Roll et al. 2006)

444 constrains their activity to the periods of the day with dim light conditions. According to the predation

445 risk allocation hypothesis (Lima \& Bednekoff 1999) if high-risk periods are frequent or lengthy, then

446 an animal has little choice but to feed under high risk. This means that murid rodents have no choice

447 but to venture during the periods of high predation risk imposed by mesocarnivore activity. In this case,

448 the probability of an individual of the prey species being killed by predation is lower when activity is

449 synchronized among its community and span for a longer period of the day, instead of being

450 concentrated in time (Halle 2000). This favours the observed unimodal and continuous pattern activity

451 observed throughout the nighttime of murid rodents in all studied areas. 
454 The constant arms race that takes place between predators and prey, and how it shapes community structure and behaviour has been matter of intense study and controversy (e.g. Blumstein 2008;

456 Dickman 2008; Gompper \& Vanak 2008; Shanas et al. 2008; Shapira et al. 2008). It is, however, widely accepted that adaptations are bidirectional and take place over at least two dimensions: spatial

458 and temporal (Lima \& Bednekoff 1999; Lima 2002). Our work focuses on the temporal component, 459 and provides some interesting insights into the structure of predator and prey adaptations. Contrary to 460 our predictions, we found that in spite of the higher energetic input provided by preying on European 461 rabbits (when compared to rodents), mesocarnivores do not completely track its activity pattern. This 462 observation is irrespective to European rabbit's abundance. We found however, that mesocarnivores, as 463 a community, tend to track small mammals activity irrespective to the ecoregion, and even though a 464 preferred or more profitable prey is available. The somewhat constant and long period of activity of rodent prey may allow predators to explore this resource sequentially, thus avoiding agonistic

466 encounters among intraguild competitors. Conversely, concentrating in the short period of time when

467 European rabbits peak their activity would probably potentiate these encounters, and consequently

468 enhance competition stress. Further research should focus on the evaluation of the spatial variation of 469 these temporal strategies in relation to microhabitat, as predation risk and prey vulnerability may differ 470 over a small spatial scale, thus leading to an adjustment of the behaviours of both predator and prey

471 species (Fenn \& MacDonald 1995; Lima \& Bednekoff 1999; Quinn \& Cresswell 2004).

\section{Acknowledgments}

This work was partially supported by a PhD grant from the Fundação para a Ciência e a Tecnologia

476 (FCT) to PM (SFRH/BD/37795/2007) and two research projects, one from the Spanish National Plan (project ref: CGL2009-10741) funded by the Spanish Ministry of Science and Innovation and EU-

478 FEDER funds, and one from the Spanish Organismo Autónomo Parques Nacionales (project ref:

479 OAPN 352/2011). We thank Ana Marta Serronha, Pedro Moreira, Ricardo Silva, Rafaela Carreira, 480 Pedro Rebelo, Francisco Díaz-Ruiz and Jesus Caro for their assistance during the fieldwork. We 481 acknowledge the staff from all the protected areas where field work was carried on, for their support 

anonymous referees.

\section{References}

Arias-Del Razo I, Hernández L, Laundré JW, Myers O (2011) Do predator and prey foraging activity patterns match? A study of coyotes (Canis latrans), and lagomorphs (Lepus californicus and Sylvilagus audobonii). J Arid Environ 75: 112-118. DOI: 10.1016/j.jaridenv.2010.09.008

Ashby K (1972) Patterns of daily activity in mammals. Mamm Rev 1: 171-185. DOI: 10.1111/j.1365-

Bakker ES, Reiffers RC, Olff H, Gleichman JM (2005) Experimental manipulation of predation risk and food quality: effect on grazing behaviour in a central-place foraging herbivore. Oecologia 146: 157-67. DOI: 10.1007/s00442-005-0180-7.

Bartness TJ, Albers HE (2000) Activity Patterns and the Biological Clock in Mammals. In Halle S, Stenseth NC (eds) Activity Patterns in Small Mammals: An Ecological Approach. Springer, New York, pp. 23-47.

Blanco JC (1998) Mamíferos de España. Planeta, Barcelona.

Blumstein DT (2008) Does agriculture drive predator-mediated behavioral effects on prey? Anim Conserv 11: 9-10. DOI: 10.1111/j.1469-1795.2008.00158.x

Brown JS, Laundre JW, Mahesh G (1999) The ecology of fear: optimal foraging, game theory, and trophic interactions. J Mammal 80: 385-399. DOI: 10.2307/1383287

Carothers JH, Jaksić FM (1984) Time as a Niche Difference: The Role of Interference Competition. Oikos 42: 403-406.

505 Carvalho JC, Gomes P (2004) Feeding resource partitioning among four sympatric carnivores in the Peneda-Gerês National Park (Portugal). J Zool 263: 275-283. DOI: $10.1017 / \mathrm{S} 0952836904005266$

Costa JC, Aguiar C, Capelo JH, Lousã M, Neto C (1998) Biogeografia de Portugal continental. Quercetea 0: 5-56.

510 Davis ML, Kelly MJ, Stauffer DF (2011) Carnivore co-existence and habitat use in the Mountain Pine Ridge Forest Reserve, Belize. Anim Conserv 14: 56-65. DOI: 10.1111/j.14691795.2010.00389.x Species of Sciurid Rodents. Biol Rhythm Res 35: 13-33. DOI: $10.1080 / 09291010412331313214$ 
Delibes M, Aymerich M, Cuesta L (1984) Feeding habits of the Herpestes ichneumon or Egyptian mongoose in Spain. Acta Theriol 29: 205-218.

518 Delibes M, Hiraldo F (1981) The rabbit as prey in the Iberian Mediterranean ecosystem. In Myers K, MacInnes CD (eds) Proceedings of the World Lagomorph Conference, University of Guelph, Ontario, pp. 614-622.

Delibes-Mateos M, Delibes M, Ferreras P, Villafuerte, R. (2008a) Key role of European rabbits in the conservation of the Western Mediterranean basin hotspot. Conserv Biol 22: 1106-17. DOI: 10.1111/j.1523-1739.2008.00993.x

Delibes-Mateos M, Fernández-de-Simón J, Villafuerte R, Ferreras P (2008b) Feeding responses of the red fox (Vulpes vulpes) to different wild rabbit (Oryctolagus cuniculus) densities: a regional approach. Eur J Wildl Res 54: 71-78. DOI: 10.1007/s10344-007-0111-5

Díaz-Ruiz F, Delibes-Mateos M, García-Moreno JL, López-Martin JM, Ferreira C, Ferreras P (2013) Biogeographical patterns in the diet of an opportunistic predator: the red fox Vulpes vulpes in the Iberian Peninsula. Mamm Rev 43: 59-70. DOI: 10.1111/j.1365-2907.2011.00206.x

Dickman CR (2008) Indirect interactions and conservation in human-modified environments. Anim Conserv 11: 11-12. DOI: 10.1111/j.1469-1795.2008.00159.x

Díez C, Pérez JA, Prieto R, Alonso ME, Olmedo JA (2005) Activity patterns of wild rabbit (Oryctolagus cuniculus, L. 1758), under semi-freedom conditions, during Autumn and Winter. Wildl Biol Pract 1: 41-46. DOI: 10.2461/wbp.2005.1.6

Ebensperger L, Wallem P (2002) Grouping increases the ability of the social rodent, Octodon degus, to detect predators when using exposed microhabitats. Oikos 98: 490-496. DOI: 10.1034/j.16000706.2002.980313.x

538 Elton CS (2001) Animal Ecology. University of Chicago Press, Chicago.

Eriksen A, Wabakken P, Zimmermann B, Andreassen HP, Arnemo JM, Gundersen H, Liberg O, Linnell J, Milner JM, Pedersen HC, Sand H, Solberg EJ, Storaas T (2011) Activity patterns of predator and prey: a simultaneous study of GPS-collared wolves and moose. Anim Behav 81: 423-431. DOI: 10.1016/j.anbehav.2010.11.011

Fedriani JM, Palomares F, Delibes M (1999) Niche relations among three sympatric Mediterranean carnivores. Oecologia 121: 138-148. DOI: 10.1007/s004420050915.

545 Fenn MGP, MacDonald DW (1995) Use of middensby red foxes: risk reverses rhythms of rats. J Mammal 76:130-136.

547 Fernández-de-Simón J, Díaz-Ruiz F, Cirilli F, Tortosa FS, Villafuerte R, Delibes-Mateos M, Ferreras P 548 (2011) Towards a standardized index of European rabbit abundance in Iberian Mediterranean habitats. Eur J Wildl Res 57: 1091-1100. DOI: 10.1007/s10344-011-0524-z 

entre la presión de depredación y los ritmos de actividad del conejo de monte: aplicación a las estimas de densidad. IX SECEM Conference, Bilbao. [in spanish]

Fernández-Durán JJ (2004) Circular Distributions Based on Nonnegative Trigonometric Sums. Biometrics 60: 499-503. DOI: 10.1111/j.0006-341X.2004.00195.x

Ferrer M, Negro JJ (2004) The Near Extinction of Two Large European Predators: Super Specialists Pay a Price. Conserv Biol 18: 344-349. DOI: 10.1111/j.1523-1739.2004.00096.x

Flowerdew JR (2000) Wood Mice - Small Granivores/Insectivores with Seasonally Variable Patterns. In Halle S, Stenseth NC (eds) Activity Patterns in Small Mammals: An Ecological Approach. Springer, New York, pp. 177-189.

García-Canseco V (1997) Parque Nacional de Cabañeros, 1st edn. Ecohábitat, Madrid.

Germain E, Benhamou S, Poulle M-L (2008) Spatio-temporal sharing between the European wildcat, the domestic cat and their hybrids. J Zool 276: 195-203. DOI:10.1111/j.14697998.2008.00479.x

Halle S (2000) Ecological Relevance of Daily Activity Patterns. In Halle S, Stenseth NC (eds) Activity Patterns in Small Mammals: An Ecological Approach. Springer, New York, pp. 67-90.

Halle S, Stenseth NC (2000) Introduction. In Halle S, Stenseth NC (eds) Activity Patterns in Small Mammals: An Ecological Approach. Springer, New York, pp. 4-17.

ICN - Instituto para a Conservação da Natureza (2006) Zona de Protecção Especial Vale do Guadiana. , 12. [in portuguese]

Jacob J, Brown JS (2000) Microhabitat use, giving-up densities and temporal activity as short- and

Jedrzejewska B, Jedrzejewski W (1990) Antipredatory behaviour of bank voles and prey choice of weasels - enclosure experiments. Ann Zool Fenn 27: 321-328.

Jilge B, Hudson R (2001) Diversity and development of circadian rhythms in the European rabbit. long-term anti-predator behaviors in common voles. Oikos 91: 131-138. DOI: 10.1034/j.16000706.2000.910112.x Chronobiol Int 18: 1-26. DOI: 10.1081/CBI-100001275

Kavanau JL and Ramos J (1975) Influences of Light on Activity and Phasing of Carnivores. Am Nat 109: 391-418. DOI: $10.1086 / 283009$ Across Species, and Habitat Selection by Species, on Salt Pond Mountain, Giles County, 
Kotler BP, Brown JS, Dall SRX, Gresser S, Ganey D, Bouskila A (2002) Foraging games between gerbils and their predators: temporal dynamics of resource depletion and apprehension in gerbils. Evol Ecol Res 4: 495-518.

Kronfeld-Schor N, Dayan T (2003) Partitioning of time as an ecological resource. Annu. Rev. Ecol. Syst 34: 153-181. DOI: 10.1146/annurev.ecolsys.34.011802.132435

Kronfeld-Schor N, Dayan T (2008) Activity patterns of rodents: the physiological ecology of biological rhythms. Biol Rhythm Res 39: 193-211. DOI: 10.1080/09291010701683268

Lima SL (2002) Putting predators back into behavioral predator-prey interactions. Trends Ecol Evol 17: 70-75. DOI: 10.1016/S0169-5347(01)02393-X

Lima SL, Bednekoff PA (1999) Temporal Variation in Danger Drives Antipredator Behavior: The Predation Risk Allocation Hypothesis. Am Nat 153: 649-659. DOI:

Linkie M, Ridout MS (2011) Assessing tiger-prey interactions in Sumatran rainforests. J Zool 284: 224-229. DOI: 10.1111/j.1469-7998.2011.00801.x

Lombardi L, Fernández N, Moreno S, Villafuerte R (2003) habitat-related differences in rabbit (Oryctolagus cuniculus) abundance, distribution, and activity. J Mammal 84: 26-36. DOI: 10.1644/1545-1542(2003)084<0026:HRDIRO>2.0.CO;2

Lozano J, Moleón M, Virgós E (2006) Biogeographical patterns in the diet of the wildcat, Felis silvestris Schreber, in Eurasia: factors affecting the trophic diversity. J Biogeogr 33: 1076-1085. DOI: $10.1111 /$ j.1365-2699.2006.01474.x

Lucherini M, Reppucci J, Walker R., Villalba M, Wurstten A, Gallardo G, Iriarte A, Villalobos R, Perovic P (2009) Activity pattern segregation of carnivores in the high Andes. J Mammal 90: 1404-1409. DOI: 10.1644/09-MAMM-A-002R.1

608 MacArthur RH, Pianka ER (1966) On the optimal use of a patchy environment. Am Nat 100: 603-609.

609 Malo AF, Lozano J, Huertas DL, Virgós E (2004) A change of diet from rodents to rabbits (Oryctolagus cuniculus). Is the wildcat (Felis silvestris) a specialist predator? J Zool 263: 401407. DOI: $10.1017 / \mathrm{S} 0952836904005448$

Marinis A, Masseti M (1995) Feeding habits of the pine marten Martes martes L., 1758, in Europe: a review. Hystrix 7: 143-150. DOI: 10.4404/hystrix-7.1-2-4063

614 Monterroso P, Alves PC, Ferreras P (2011) Evaluation of attractants for non-invasive studies of Iberian carnivore communities. Wildl Res 38: 446-454. DOI: 10.1071/WR11060 of vegetation by European wild rabbits. Can J Zool 74: 1656-1660. DOI: 10.1139/z96-183 
Moseby KE, De Jong S, Munro N, Pieck A (2005) Home range, activity and habitat use of European rabbits (Oryctolagus cuniculus) in arid Australia: implications for control. Wildl Res 32: 305311. DOI: 10.1071/WR04013

621 Palomares F, Delibes M (2000) Mongooses, Civets and Genets - Carnivores in Southern Latitudes. In Halle S, Stenseth NC (eds) Activity Patterns in Small Mammals: An Ecological Approach. Springer, New York, Pp: 119-130.

Palomares F, Gaona P, Ferreras P, Delibes M (1995) Positive Effects on Game Species of Top Predators by Controlling Smaller Predator Populations: An Example with Lynx, Mongooses, and Rabbits. Conserv Biol 9: 295-305. DOI: 10.1046/j.1523-1739.1995.9020295.x

Palomares, F. (2001) Comparison of 3 methods to estimate rabbit abundance in a Mediterranean environment. Wildl Soc Bull 29: 578-585.

Palomo LJ, Justo ER, Vargas JM (2009) Mus spretus (Rodentia: Muridae). Mammal Species 840: 110. DOI: $10.1644 / 840.1$

Pech RP, Sinclair ARE, Newsome AE, Catling PC (1992) Limits to predator regulation of rabbits in Australia: evidence from predator-removal experiments. Oecologia 89: 102-112. DOI: 10.1007/BF00319021

Pierce B, Longland W, Jenkins S (1992) Rattlesnake Predation on Desert Rodents: Microhabitat and Species-Specific Effects on Risk. J Mammal 73: 859-865.

Prieto JAF, Sánchez ÁB (1996) La Reserva Integral de Muniellos: Flora y Vegetación. Servicio central de publicaciones del Principado de Asturias, Oviedo. [in spanish]

Pyke GH, Pulliam HR, Charnov EL (1977) Optimal Foraging: A Selective Review of Theory and Tests. Q Rev Biol 52: 137-154.

640 Quinn JL, Cresswell W (2004) Predator hunting behaviour and prey vulnerability. J Anim Ecol 73: 143-154. DOI: 10.1046/j.0021-8790.2004.00787.x

642 R Development Core Team. 2008. R: A language and environment for statistical computing.

643 Ridout MS, Linkie M (2009) Estimating overlap of daily activity patterns from camera trap data. J

644 Agric Biol Environ Stat 14: 322-337. DOI: 10.1198/jabes.2009.08038

Ripple WJ, Beschta RL (2004) Wolves and the Ecology of Fear: Can Predation Risk Structure Ecosystems? BioScience 54: 755-766. DOI: 10.1641/00063568(2004)054[0755:WATEOF]2.0.CO;2

Rivas-Martínez S (1981) Les étages bioclimatiques de la végétation de la Peninsule Iberique. Anales Jard. Bot. Madrid 37: 251-268. http://www.ucm.es/info/cif/form/maps.htm 
Roll U, Dayan T, Kronfeld-Schor N (2006) On the role of phylogeny in determining activity patterns of rodents. Evol Ecol 20. 479-490. DOI: 10.1007/s10682-006-0015-y

Roth II TC, Lima SL (2007) The predatory behavior of wintering Accipiter hawks: temporal patterns in activity of predators and prey. Oecologia, 152: 169-178. DOI: 10.1007/s00442-006-0638-2

Schoener, T.W. (1974) Resource partitioning in ecological communities. Science 185: 27-39. DOI: 10.1126/science. 185.4145 .27

Shanas U, Shapira I and Sultan H (2008) Behavioural alterations as part of an agricultural edge effect. Anim Conserv 11: 15-16. DOI: 10.1111/j.1469-1795.2008.00161.x

Shapira I, Sultan H and Shanas U (2008) Agricultural farming alters predator-prey interactions in nearby natural habitats. Anim Conserv 11: 1-8. DOI: 10.1111/j.1469-1795.2007.00145.x

Sih A, McCarthy T (2002) Prey responses to pulses of risk and safety: testing the risk allocation hypothesis. Anim Behav 63: 437-443. DOI: 10.1006/anbe.2001.1921 Predation on Conservation of Endangered Prey. Conserv Biol 12: 564-575. DOI: 10.1111/j.1523-1739.1998.97030.x

Trout RC, Tittensor AM (1989) Can predators regulate wild Rabbit Oryctolagus cuniculus population density in England and Wales. Mammal Rev 19: 153-173. DOI: 10.1111/j.13652907.1989.tb00409.x

UNESCO. UNESCO - MAB Biosphere Reserve Directory, http://www.unesco.org/mabdb/br/brdir/directory/database.asp

Villafuerte R, Kufner,MB, Delibes M, Moreno (1993) Environmental factors influencing the seasonal daily activity of the European rabbit (Oryctolagus cuniculus) in a Mediterranean area. Mammalia 57: 341-347. DOI: 10.1515/mamm.1993.57.3.341

Villafuerte, R. and Moreno, S. (1997) Predation risk, cover type, and group size in European rabbits in Doñana (SW Spain). Acta Theriol 42: 225-230. DOI: oai:rcin.org.pl:12688

Virgós E, Llorente M, Cortés Y (1999) Geographical variation in genet (Genetta genetta L.) diet: a literature review. Mammal Rev 29: 119-128. DOI: 10.1046/j.1365-2907.1999.00041.x

Virgós E, Revilla E, Mangas JG, Barea-Azcón JM, Rosalino, ML, Marinis A (2005) Revisión de la dieta del Téjon (Meles meles) en la Península Ibérica: comparación con otras localidades de su área de distribución natural. In Virgós E, Mangas JG, Revilla E, Roura X-D (eds) Ecología, distribución y estatus de conservación del tejón Ibérico. Sociedad Española para la Conservación y Estudio de los Mamíferos, Málaga. Pp 67-80. small mammals. Eur J Wildl Res 56: 261-274. DOI: 10.1007/s10344-009-0308-X 
686 Weckel M, Giuliano W, Silver S (2006) Jaguar (Panthera onca) feeding ecology: distribution of predator and prey through time and space. J Zool 270: 25-30. DOI:10.1111/j.14697998.2006.00106.x.

689 Wolton,BYRJ (1983) The Activity of Free-Ranging Wood Mice Apodemus sylvaticus. J Anim Ecol 52:

690 781-794.

691 Zalewski A (2000) Factors affecting the duration of activity by pine martens (Martes martes) in the Bialowieza National Park, Poland. J Zool 251: 439-447. DOI: 10.1111/j.14697998.2000.tb00799.x

694 Zhou Y, Newman C, Xu W, Buesching CD, Zalewski A, Kaneko Y, Macdonald DW, Xie Z-Q (2011) Biogeographical variation in the diet of Holarctic martens (genus Martes, Mammalia: Carnivora: Mustelidae): adaptive foraging in generalists. J Biogeogr 38: 137-147. DOI: 


\section{Tables}

Table 1. Number of independent camera-trap detections and relative contributions of each species for mesocarnivore and prey community data structures.

\begin{tabular}{|c|c|c|c|c|c|c|c|c|}
\hline \multirow[t]{2}{*}{ Species } & \multicolumn{2}{|c|}{ CNP } & \multicolumn{2}{|c|}{ GVNP } & \multicolumn{2}{|c|}{ PGNP } & \multicolumn{2}{|c|}{ MNR } \\
\hline & Autumn & Spring & Autumn & Spring & Autumn & Spring & Autumn & Spring \\
\hline Small mammals & 105 & 143 & 44 & 77 & 186 & 13 & 135 & 55 \\
\hline European rabbit & 48 & 15 & 1705 & 1074 & 2 & 0 & 0 & 0 \\
\hline Red fox & $259(76.0 \%)$ & $382(86.2 \%)$ & $40(33.3 \%)$ & $7(5.11 \%)$ & $22(34.9 \%)$ & $12(16.4 \%)$ & $6(8.8 \%)$ & $22(34.4 \%$ \\
\hline European wildcat & $4(1.2 \%)$ & $7(1.6 \%)$ & $22(18.3 \%)$ & $19(13.9 \%)$ & $1(1.6 \%)$ & $7(9.6 \%)$ & $9(13.2 \%)$ & $7(10.9 \%)$ \\
\hline Stone marten & $42(12.3 \%)$ & $24(5.4 \%)$ & $16(13.3 \%)$ & $58(42.3 \%)$ & $3(4.8 \%)$ & $12(16.4 \%)$ & $1(1.5 \%)$ & $2(3.1 \%)$ \\
\hline Pine marten & 0 & 0 & 0 & 0 & $13(20.6 \%)$ & $27(37.0 \%)$ & $40(58.8 \%)$ & $27(42.2 \%$ \\
\hline Marten spp.* & 0 & 0 & 0 & 0 & $12(19.1 \%)$ & $6(8.2 \%)$ & $4(5.9 \%)$ & $2(3.1 \%)$ \\
\hline Eurasian badger & $15(4.4 \%)$ & $8(1.8 \%)$ & $12(10.0 \%)$ & $5(3.6 \%)$ & 0 & $1(1.4 \%)$ & $1(1.5 \%)$ & $2(3.1 \%)$ \\
\hline Common genet & $21(6.16 \%)$ & $16(3.6 \%)$ & $8(6.7 \%)$ & $30(21.9 \%)$ & $12(19.1 \%)$ & $8(11.0 \%)$ & $7(10.3 \%)$ & $2(3.1 \%)$ \\
\hline Egyptian mongoose & 0 & $6(1.4 \%)$ & $22(18.3 \%)$ & $18(13.1 \%)$ & 0 & 0 & 0 & 0 \\
\hline $\begin{array}{l}\text { Mesocarnivore } \\
\text { community }\end{array}$ & 341 & 443 & 120 & 137 & 63 & 73 & 68 & 64 \\
\hline
\end{tabular}

* - Photographs in which it was impossible to distinguish between pine marten and stone marten. 
Table 2. Prey species relative abundance in the study areas. European rabbit - pellet production $\cdot 100$ days ${ }^{-1} \cdot \mathrm{m}^{-2}$; Murinae spp. - Apodemus sp. and Mus sp. new captures $\cdot 100$ trapping days $\mathrm{s}^{-1}$. Results presented as average \pm standard error. Note that units are different for both prey types.

\begin{tabular}{l|c|c|c|c|c|c|c|c}
\hline \multirow{2}{*}{ Species } & \multicolumn{2}{c|}{ CNP } & \multicolumn{2}{c|}{ GVNP } & \multicolumn{2}{c}{ PGNP } & \multicolumn{2}{c}{ MNR } \\
\cline { 2 - 10 } & Autumn & Spring & Autumn & Spring & Autumn & Spring & Autumn & Spring \\
\hline European rabbit & $6.7 \pm 3.4$ & $16.2 \pm 6.8$ & $179.5 \pm 31.6$ & $170.2 \pm 31.4$ & $0.0 \pm 0.0$ & $0.0 \pm 0.0$ & $0.1 \pm 0.1$ & $0.0 \pm 0.0$ \\
\hline Murinae spp. & $3.07 \pm 0.95$ & $5.15 \pm 2.18$ & $6.97 \pm 1.97$ & $5.52 \pm 2.52$ & $10.82 \pm 2.35$ & $2.23 \pm 1.44$ & $6.52 \pm 2.23$ & $4.42 \pm 0.24$ \\
\hline
\end{tabular}


Table 3. Density of activity (number of detections hour ${ }^{-1} 100$ trap-days $^{-1}$ ) of each species and mesocarnivore community, for each period considered of day: $\mathrm{N}$ - Nighttime, C - Crepuscular, D - Daytime.

\begin{tabular}{|c|c|c|c|c|c|c|c|c|c|c|c|c|c|c|c|c|c|c|c|c|c|c|c|c|}
\hline \multirow{3}{*}{ Species } & \multicolumn{6}{|c|}{ CNP } & \multicolumn{6}{|c|}{ GVNP } & \multicolumn{6}{|c|}{ PGNP } & \multicolumn{6}{|c|}{ MNR } \\
\hline & \multicolumn{3}{|c|}{ Autumn } & \multicolumn{3}{|c|}{ Spring } & \multicolumn{3}{|c|}{ Autumn } & \multicolumn{3}{|c|}{ Spring } & \multicolumn{3}{|c|}{ Autumn } & \multicolumn{3}{|c|}{ Spring } & \multicolumn{3}{|c|}{ Autumn } & \multicolumn{3}{|c|}{ Spring } \\
\hline & $\mathbf{N}$ & C & D & $\mathbf{N}$ & C & D & $\mathbf{N}$ & $\mathbf{C}$ & D & $\mathbf{N}$ & C & D & $\mathbf{N}$ & C & D & $\mathbf{N}$ & C & D & $\mathbf{N}$ & C & D & $\mathbf{N}$ & C & D \\
\hline $\begin{array}{l}\text { European } \\
\text { rabbit }\end{array}$ & 0.02 & 0.42 & 0.23 & 0.05 & 0.17 & 0.02 & 7.07 & $\begin{array}{c}17.2 \\
0\end{array}$ & 4.09 & 3.18 & 8.00 & 6.90 & 0.01 & 0.03 & 0.00 & 0.00 & 0.00 & 0.00 & 0.00 & 0.00 & 0.00 & 0.00 & 0.00 & 0.00 \\
\hline $\begin{array}{l}\text { Small } \\
\text { mammals }\end{array}$ & 0.75 & 0.15 & 0.03 & 1.14 & 0.19 & 0.00 & 0.53 & 0.00 & 0.00 & 0.89 & 0.19 & 0.00 & 1.62 & 0.31 & 0.00 & 0.13 & 0.05 & 0.00 & 1.20 & 0.18 & 0.00 & 0.48 & 0.00 & 0.00 \\
\hline Red fox & 1.38 & 1.16 & 0.26 & 1.89 & 1.64 & 1.02 & 0.26 & 0.36 & 0.04 & 0.21 & 0.00 & 0.00 & 0.18 & 0.08 & 0.00 & 0.09 & 0.05 & 0.02 & 0.05 & 0.02 & 0.00 & 0.18 & 0.04 & 0.00 \\
\hline $\begin{array}{l}\text { European } \\
\text { wildcat }\end{array}$ & 0.02 & 0.00 & 0.01 & 0.06 & 0.00 & 0.00 & 0.22 & 0.08 & 0.01 & 0.12 & 0.15 & 0.05 & 0.01 & 0.00 & 0.00 & 0.00 & 0.02 & 0.05 & 0.05 & 0.02 & 0.03 & 0.04 & 0.02 & 0.01 \\
\hline Stone marten & 0.32 & 0.02 & 0.00 & 0.20 & 0.00 & 0.00 & 0.19 & 0.00 & 0.00 & 0.64 & 0.19 & 0.00 & 0.02 & 0.03 & 0.00 & 0.12 & 0.02 & 0.00 & 0.00 & 0.02 & 0.00 & 0.02 & 0.00 & 0.00 \\
\hline Pine marten & - & - & - & - & - & - & - & - & - & - & - & - & 0.09 & 0.08 & 0.00 & 0.15 & 0.15 & 0.06 & 0.24 & 0.20 & 0.05 & 0.15 & 0.15 & 0.04 \\
\hline $\begin{array}{l}\text { Eurasian } \\
\text { badger }\end{array}$ & 0.13 & 0.08 & 0.00 & 0.14 & 0.00 & 0.00 & 0.08 & 0.03 & 0.00 & 0.33 & 0.09 & 0.00 & 0.11 & 0.00 & 0.00 & 0.09 & 0.00 & 0.00 & 0.07 & 0.00 & 0.00 & 0.02 & 0.00 & 0.00 \\
\hline Common genet & 0.12 & 0.00 & 0.00 & 0.06 & 0.00 & 0.01 & 0.14 & 0.00 & 0.00 & 0.06 & 0.00 & 0.00 & 0.00 & 0.00 & 0.00 & 0.01 & 0.00 & 0.00 & 0.01 & 0.00 & 0.00 & 0.02 & 0.00 & 0.00 \\
\hline $\begin{array}{l}\text { Egyptian } \\
\text { mongoose }\end{array}$ & 0.00 & 0.00 & 0.00 & 0.00 & 0.00 & 0.07 & 0.00 & 0.05 & 0.18 & 0.00 & 0.03 & 0.21 & - & - & - & - & - & - & - & - & - & - & - & - \\
\hline $\begin{array}{l}\text { Mesocarnivore } \\
\text { community }\end{array}$ & 1.98 & 1.27 & 0.27 & 2.35 & 1.64 & 1.09 & 0.90 & 0.51 & 0.23 & 1.37 & 0.46 & 0.26 & 0.50 & 0.23 & 0.00 & 0.53 & 0.30 & 0.13 & 0.43 & 0.29 & 0.08 & 0.43 & 0.20 & 0.05 \\
\hline
\end{tabular}


Table 4. Coefficient of overlap $\left(\Delta_{4}\right)$ between terrestrial carnivores, small mammals and European rabbits (estimate and [95\% confidence interval]).

\begin{tabular}{|c|c|c|c|c|c|c|c|c|c|c|}
\hline $\begin{array}{c}\text { Study } \\
\text { area }\end{array}$ & Season & Prey species & Red fox & $\begin{array}{c}\text { European } \\
\text { wildcat }\end{array}$ & Stone marten & Pine marten & $\begin{array}{c}\text { Eurasian } \\
\text { badger }\end{array}$ & Common genet & $\begin{array}{l}\text { Egyptian } \\
\text { mongoose }\end{array}$ & $\begin{array}{c}\text { Mesocarnivore } \\
\text { community }\end{array}$ \\
\hline \multirow{4}{*}{ CNP } & \multirow{2}{*}{ Autumn } & $\begin{array}{c}\text { Small } \\
\text { mammals }\end{array}$ & $0.77[0.67-0.81]$ & - & $0.79[0.61-0.86]$ & - & - & $0.92[0.60-0.90]$ & - & $0.83[0.76-0.87]$ \\
\hline & & $\begin{array}{c}\text { European } \\
\text { rabbit }\end{array}$ & $0.33[0.21-0.41]$ & - & $0.12[0.04-0.19]$ & - & - & $0.17[0.05-0.26]$ & - & $0.29[0.19-0.37]$ \\
\hline & \multirow{2}{*}{ Spring } & $\begin{array}{c}\text { Small } \\
\text { mammals }\end{array}$ & $0.65[0.58-0.70]$ & - & $0.77[0.52-0.84]$ & - & - & $0.78[0.51-0.83]$ & - & $0.69[0.62-0.73]$ \\
\hline & & $\begin{array}{l}\text { European } \\
\text { rabbit }\end{array}$ & $0.65[0.34-0.75]$ & - & $0.38[0.13-0.52]$ & - & - & $0.38[0.12-0.54]$ & - & $0.64[0.35-0.75]$ \\
\hline \multirow{4}{*}{ GVNP } & \multirow{2}{*}{ Autumn } & $\begin{array}{c}\text { Small } \\
\text { mammals }\end{array}$ & $0.54[0.37-0.67]$ & $0.71[0.47-0.82]$ & $0.74[0.46-0.90]$ & - & $0.61[0.28-0.82]$ & $0.88[0.46-0.89]$ & $0.02[0.00-0.04]$ & $0.60[0.48-0.67]$ \\
\hline & & $\begin{array}{c}\text { European } \\
\text { rabbit }\end{array}$ & $0.64[0.47-0.68]$ & $0.46[0.28-0.56]$ & $0.33[0.17-0.35]$ & - & $0.24[0.11-0.26]$ & - & $0.30[0.16-0.40]$ & $0.65[0.54-0.70]$ \\
\hline & \multirow{2}{*}{ Spring } & $\begin{array}{c}\text { Small } \\
\text { mammals }\end{array}$ & $0.80[0.48-0.85]$ & $0.62[0.34-0.73]$ & $0.85[0.68-0.91]$ & - & - & $0.59[0.40-0.75]$ & $0.04[0.00-0.08]$ & $0.80[0.67-0.85]$ \\
\hline & & $\begin{array}{l}\text { European } \\
\text { rabbit }\end{array}$ & $0.23[0.14-0.25]$ & $0.60[0.35-0.61]$ & $0.28[0.23-0.32]$ & - & - & $0.25[0.16-0.28]$ & $0.53[0.35-0.55]$ & $0.47[0.41-0.54]$ \\
\hline \multirow{2}{*}{ PGNP } & Autumn & $\begin{array}{c}\text { Small } \\
\text { mammals }\end{array}$ & $0.82[0.52-0.86]$ & - & - & $0.77[0.39-0.84]$ & - & $0.80[0.44-0.81]$ & - & $0.89[0.73-0.91]$ \\
\hline & Spring & $\begin{array}{c}\text { Small } \\
\text { mammals }\end{array}$ & $0.67[0.25-0.82]$ & $0.09[0.00-0.16]$ & - & $0.58[0.30-0.72]$ & - & $0.73[0.28-0.85]$ & - & $0.70[0.43-0.79]$ \\
\hline \multirow{2}{*}{ MNR } & Autumn & $\begin{array}{c}\text { Small } \\
\text { mammals }\end{array}$ & - & $0.58[0.20-0.69]$ & - & $0.69[0.52-0.76]$ & - & $0.64[0.52-0.76]$ & - & $0.74[0.62-0.82]$ \\
\hline & Spring & $\begin{array}{c}\text { Small } \\
\text { mammals }\end{array}$ & $0.62[0.55-0.87]$ & $0.67[0.21-0.72]$ & - & $0.70[0.50-0.81]$ & - & - & - & $0.80[0.64-0.85]$ \\
\hline
\end{tabular}


Table 5. Pearson correlation (activity synchrony) between terrestrial carnivores, small mammals and European rabbits (estimate and [95\% confidence interval]).

\begin{tabular}{|c|c|c|c|c|c|c|c|c|c|c|}
\hline $\begin{array}{l}\text { Study } \\
\text { area }\end{array}$ & Season & $\begin{array}{c}\text { Prey } \\
\text { species }\end{array}$ & Red fox & $\begin{array}{c}\text { European } \\
\text { wildcat }\end{array}$ & Stone marten & Pine marten & $\begin{array}{c}\text { Eurasian } \\
\text { badger }\end{array}$ & Common genet & $\begin{array}{l}\text { Egyptian } \\
\text { mongoose }\end{array}$ & $\begin{array}{l}\text { Mesocarnivore } \\
\text { community }\end{array}$ \\
\hline \multirow{4}{*}{ CNP } & \multirow{2}{*}{ Autumn } & $\begin{array}{c}\text { Small } \\
\text { mammals }\end{array}$ & $\begin{array}{c}0.80 * *[0.60- \\
0.89]\end{array}$ & - & $\begin{array}{c}0.85 * *[0.57- \\
0.94]\end{array}$ & - & $\begin{array}{c}0.72 * *[0.32- \\
0.89]\end{array}$ & $\begin{array}{c}0.97 * *[0.59- \\
0.97]\end{array}$ & - & $\begin{array}{c}0.93 * *[0.79- \\
0.96]\end{array}$ \\
\hline & & $\begin{array}{l}\text { European } \\
\text { rabbit }\end{array}$ & $\begin{array}{c}-0.31 * *[-0.47-- \\
0.12]\end{array}$ & - & $\begin{array}{c}-0.40 * *[-0.55-- \\
0.23]\end{array}$ & - & $x^{2}$ & $\begin{array}{c}-0.42 * *[-0.57-- \\
0.14]\end{array}$ & - & $\begin{array}{c}-0.39 * *[-0.53-- \\
0.23]\end{array}$ \\
\hline & \multirow{2}{*}{ Spring } & $\begin{array}{c}\text { Small } \\
\text { mammals }\end{array}$ & $\begin{array}{c}0.58^{* *}[0.28- \\
0.78]\end{array}$ & - & $\begin{array}{c}0.82 * *[0.53- \\
0.92]\end{array}$ & - & - & $\begin{array}{c}0.84 * *[0.49- \\
0.91]\end{array}$ & - & $\begin{array}{c}0.74 * *[0.49- \\
0.88]\end{array}$ \\
\hline & & $\begin{array}{l}\text { European } \\
\text { rabbit }\end{array}$ & $\begin{array}{c}-0.01[-0.42- \\
0.58]\end{array}$ & - & $\begin{array}{c}-0.07[-0.42- \\
0.39]\end{array}$ & - & - & $\begin{array}{c}-0.13 * *[-0.48- \\
0.40]\end{array}$ & - & $\begin{array}{c}-0.06[-0.46- \\
0.48]\end{array}$ \\
\hline \multirow{4}{*}{ GVNP } & \multirow{2}{*}{ Autumn } & $\begin{array}{c}\text { Small } \\
\text { mammals }\end{array}$ & $\begin{array}{c}0.40 * *[0.09- \\
0.66]\end{array}$ & $\begin{array}{c}0.83 * *[0.36- \\
0.94]\end{array}$ & $\begin{array}{c}0.77 * *[0.35- \\
0.96]\end{array}$ & - & $\begin{array}{c}0.66 * *[0.24- \\
0.91]\end{array}$ & $\begin{array}{c}0.97 * *[0.47- \\
0.97]\end{array}$ & $\begin{array}{c}-0.68 * *[-0.80-- \\
0.40]\end{array}$ & $\begin{array}{c}0.78 * *[0.49- \\
0.89]\end{array}$ \\
\hline & & $\begin{array}{c}\text { European } \\
\text { rabbit }\end{array}$ & $\begin{array}{c}0.66 * *[0.32- \\
0.79]\end{array}$ & $\begin{array}{c}0.17 * *[-0.06- \\
0.43]\end{array}$ & $\begin{array}{c}-0.03[-0.12- \\
0.09]\end{array}$ & - & $\begin{array}{c}0.08[-0.14- \\
0.11]\end{array}$ & 型 & $\begin{array}{c}-0.15^{* *}[-0.37- \\
0.11]\end{array}$ & $\begin{array}{c}0.36 * *[0.11- \\
0.55]\end{array}$ \\
\hline & \multirow{2}{*}{ Spring } & $\begin{array}{c}\text { Small } \\
\text { mammals }\end{array}$ & $\begin{array}{c}0.88^{* *}[0.48- \\
0.94]\end{array}$ & $\begin{array}{c}0.49 * *[-0.13- \\
0.79]\end{array}$ & $\begin{array}{c}0.92 * *[0.68- \\
0.97]\end{array}$ & - & 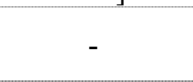 & $\begin{array}{c}0.53 * *[0.26- \\
0.78]\end{array}$ & $\begin{array}{c}-0.81 * *[-0.84-- \\
0.57]\end{array}$ & $\begin{array}{c}0.94 * *[0.72- \\
0.98]\end{array}$ \\
\hline & & $\begin{array}{l}\text { European } \\
\text { rabbit }\end{array}$ & $\begin{array}{c}-0.52 * *[-0.61-- \\
0.26]\end{array}$ & $\begin{array}{c}-0.04[-0.43- \\
0.38]\end{array}$ & $\begin{array}{c}-0.66^{* *}[-0.72-- \\
0.50]\end{array}$ & - & - & $\begin{array}{c}-0.44 * *[-0.51-- \\
0.29]\end{array}$ & $\begin{array}{c}0.46^{* *}[0.11- \\
0.59]\end{array}$ & $\begin{array}{c}-0.69 * *[-0.75-- \\
0.51]\end{array}$ \\
\hline \multirow{4}{*}{ PGNP } & \multirow{2}{*}{ Autumn } & $\begin{array}{c}\text { Small } \\
\text { mammals }\end{array}$ & $\begin{array}{c}0.86^{* *}[0.46- \\
0.93]\end{array}$ & (2) & 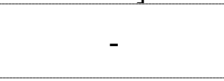 & $\begin{array}{c}0.81 * *[0.26- \\
0.90]\end{array}$ & - & $\begin{array}{c}0.84 * *[0.43- \\
0.86]\end{array}$ & $x^{2}$ & $\begin{array}{c}0.93 * *[0.68- \\
0.96]\end{array}$ \\
\hline & & $\begin{array}{l}\text { European } \\
\text { rabbit }\end{array}$ & $x^{2}$ & - & - & - & - & - & - & - \\
\hline & \multirow{2}{*}{ Spring } & $\begin{array}{c}\text { Small } \\
\text { mammals }\end{array}$ & $\begin{array}{c}0.66 * *[0.02- \\
0.92]\end{array}$ & $\begin{array}{c}-0.94 * *[-0.88-- \\
0.30]\end{array}$ & - & $\begin{array}{c}0.41 * *[-0.22- \\
0.86]\end{array}$ & - & $\begin{array}{c}0.86^{* *}[0.25- \\
0.95] \\
\end{array}$ & - & $\begin{array}{c}0.77 * *[0.24- \\
0.95]\end{array}$ \\
\hline & & $\begin{array}{c}\text { European } \\
\text { rabbit }\end{array}$ & $x^{2}$ & 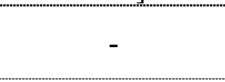 & - & 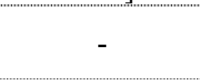 & - & 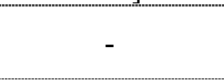 & - & 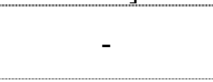 \\
\hline \multirow{4}{*}{ MNR } & \multirow{2}{*}{ Autumn } & $\begin{array}{c}\text { Small } \\
\text { mammals }\end{array}$ & - & $\begin{array}{c}0.43 * *[-0.32- \\
0.74]\end{array}$ & - & $\begin{array}{c}0.69 * *[0.32- \\
0.84]\end{array}$ & - & $\begin{array}{c}0.69 * *[0.32- \\
0.84]\end{array}$ & - & $\begin{array}{c}0.85 * *[0.57- \\
0.93]\end{array}$ \\
\hline & & $\begin{array}{l}\text { European } \\
\text { rabbit }\end{array}$ & - & - & - & - & - & - & - & - \\
\hline & \multirow{2}{*}{ Spring } & $\begin{array}{c}\text { Small } \\
\text { mammals }\end{array}$ & $\begin{array}{c}0.91^{* *}[0.50- \\
0.95]\end{array}$ & $\begin{array}{c}0.64 * *[-0.13- \\
0.80]\end{array}$ & - & $\begin{array}{c}0.82 * *[0.22- \\
0.93]\end{array}$ & - & - & - & $\begin{array}{c}0.93 * *[0.67- \\
0.95] \\
\end{array}$ \\
\hline & & $\begin{array}{c}\text { European } \\
\text { rabbit }\end{array}$ & - & - & - & - & - & - & - & - \\
\hline
\end{tabular}

* - significant correlation $(\mathrm{p}<0.05) ; * *$ - highly significant correlation $(\mathrm{p}<0.01)$. 


\section{Figures}

Figure 1. - Location of the study areas: MNR - Muniellos Natural Reserve; PGNP - Peneda-Gerês National Park; GVNP - Guadiana Valley Natural Park; CNP - Cabañeros National Park.

Figure 2. - Activity overlap between the mesocarnivore community (dashed line) and murid species (full line) in all study areas - Cabañeros National Park (CNP), Guadiana Valley Natural Park (GVNP), Muniellos Natural Reserve (MNR) and Peneda-Gerês National Park (PGNP) - during Autumn and Spring sampling campaigns, as determined by camera-trapping. Vertical dashed lines represent sunrise and sunset times, respectively.

Figure 3. - Activity overlap between the mesocarnivore community (dashed line) and European rabbits (full line) in Mediterranean study areas - Cabañeros National Park (CNP) and Guadiana Valley Natural Park (GVNP) - during Autumn and Spring sampling campaigns, as determined by camera-trapping. Vertical dashed lines represent sunrise and sunset times, respectively.

Figure 4. - Relative contributions (percentage of total number of independent photographs during a sampling campaign) of each species for mesocarnivore community data structures. (* - Photographs in which it was impossible to distinguish between pine marten and stone marten). 


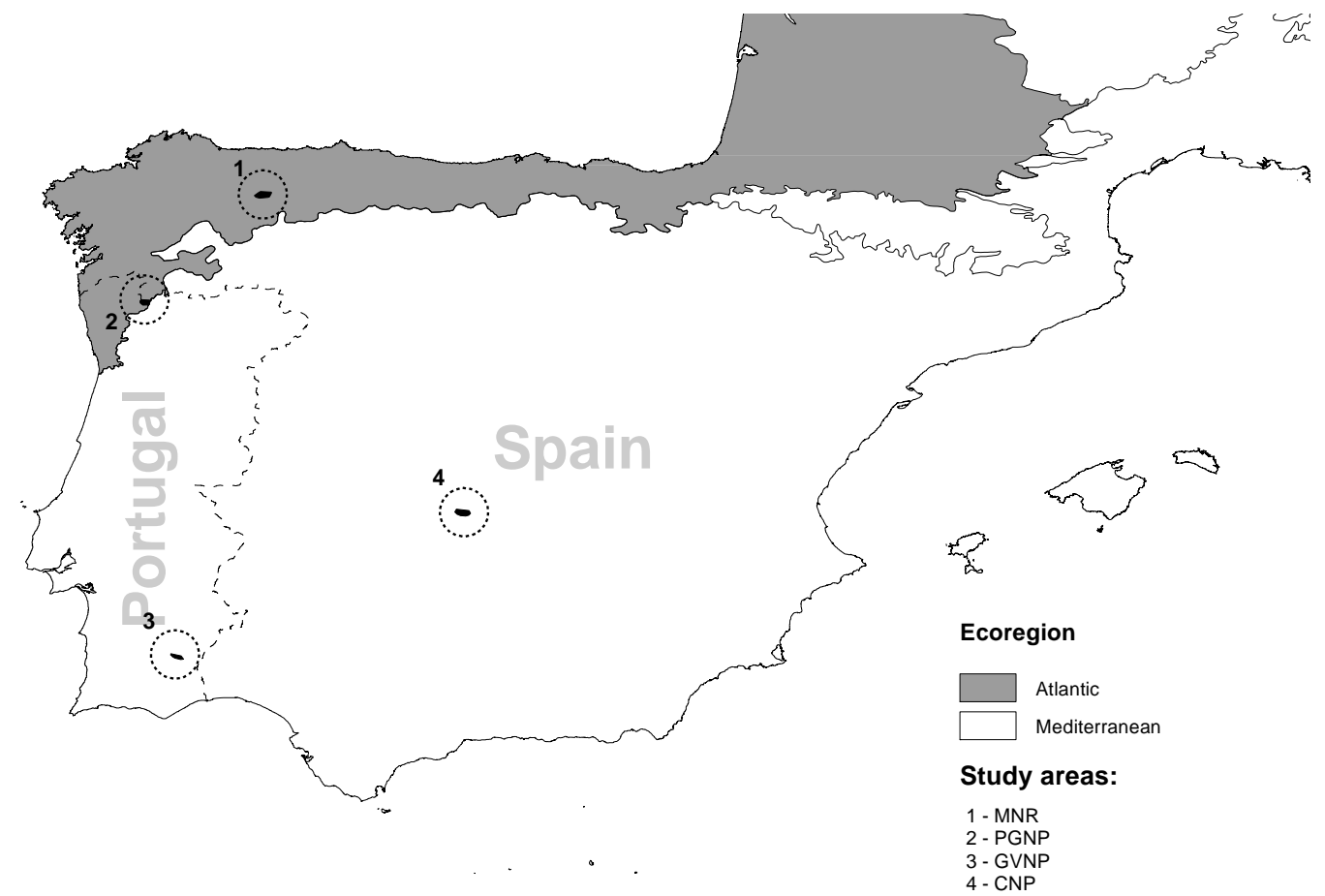

Figure 1 

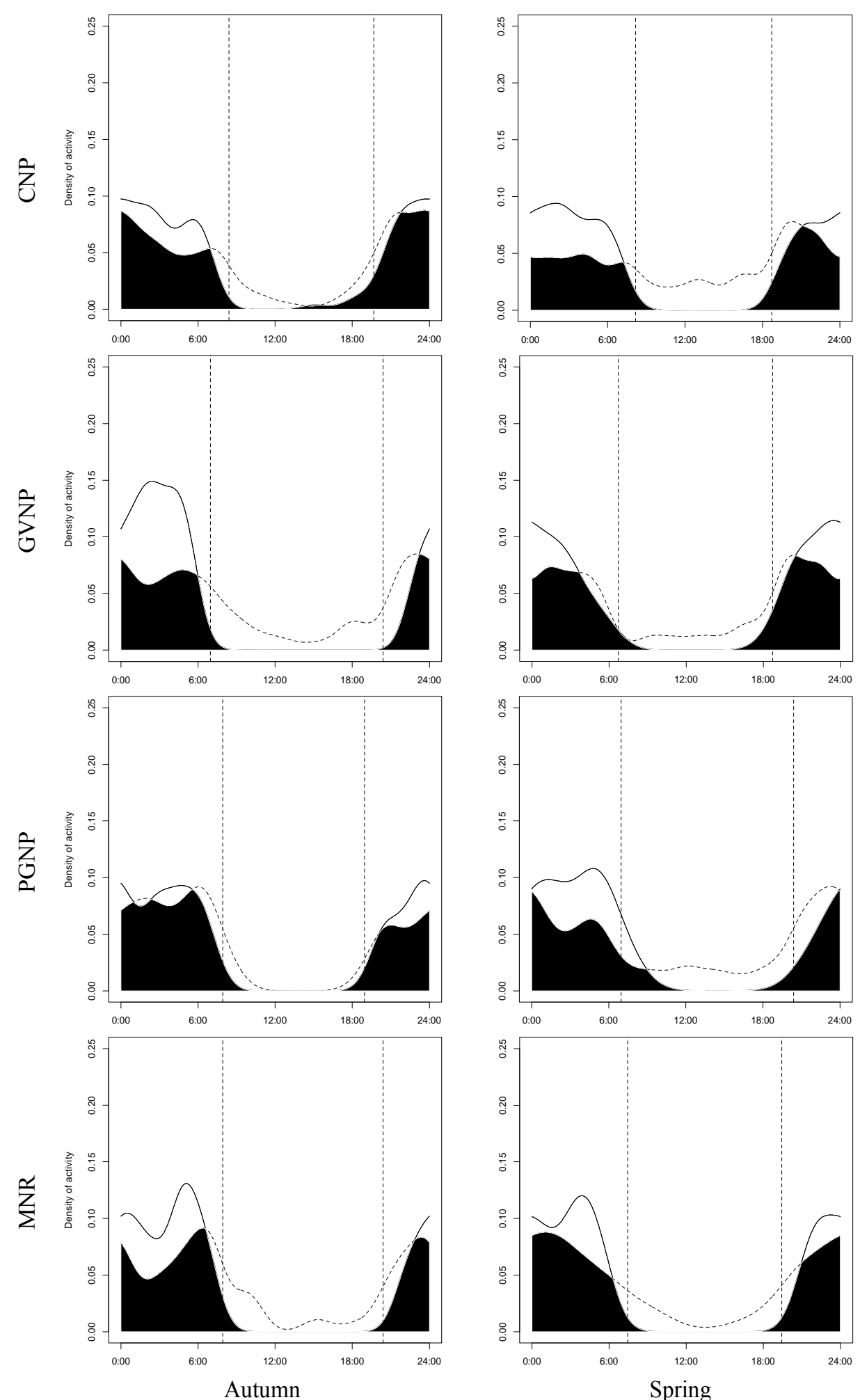

Figure 2

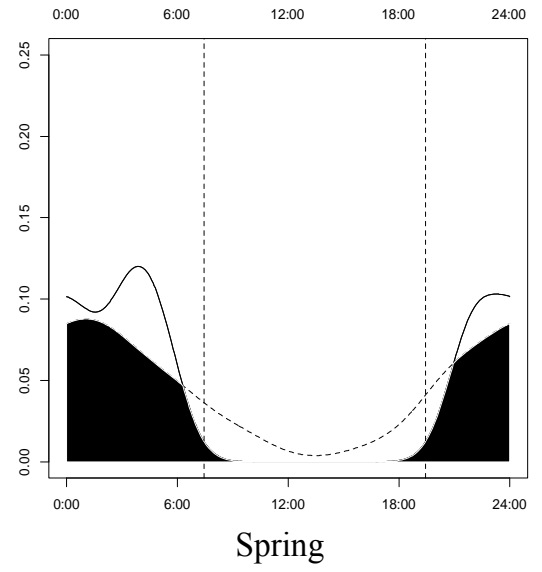



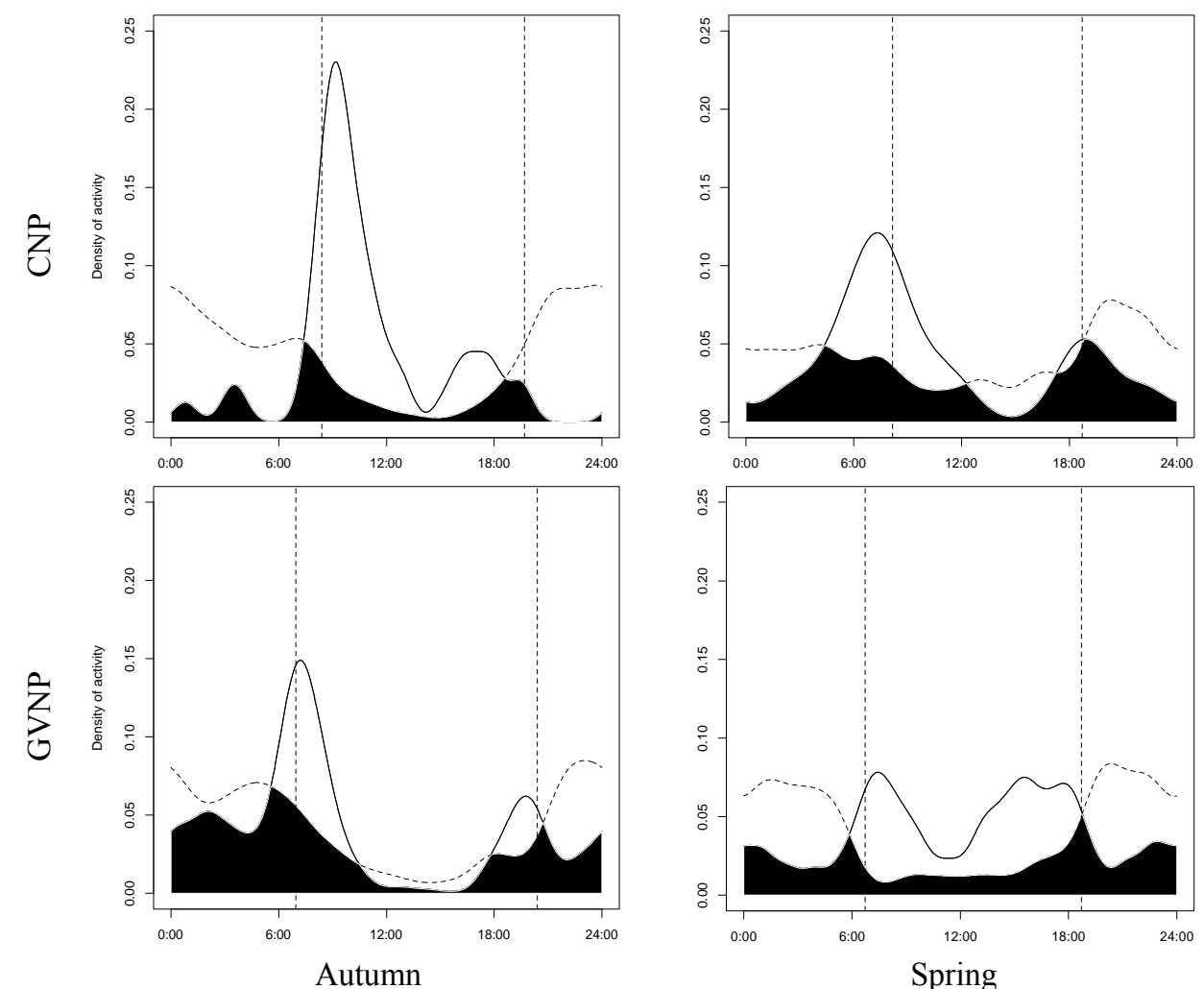

Figure 3

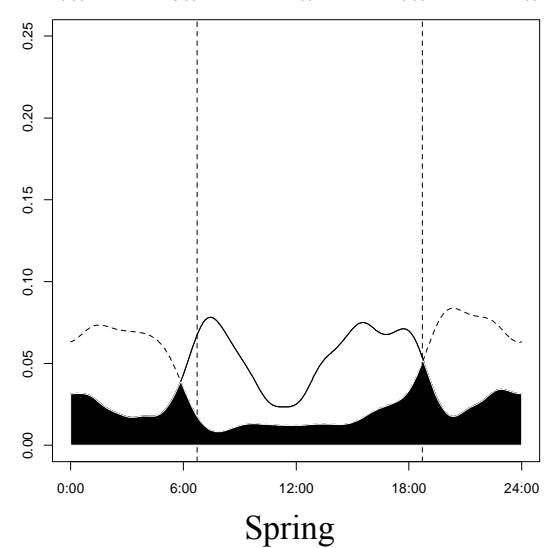




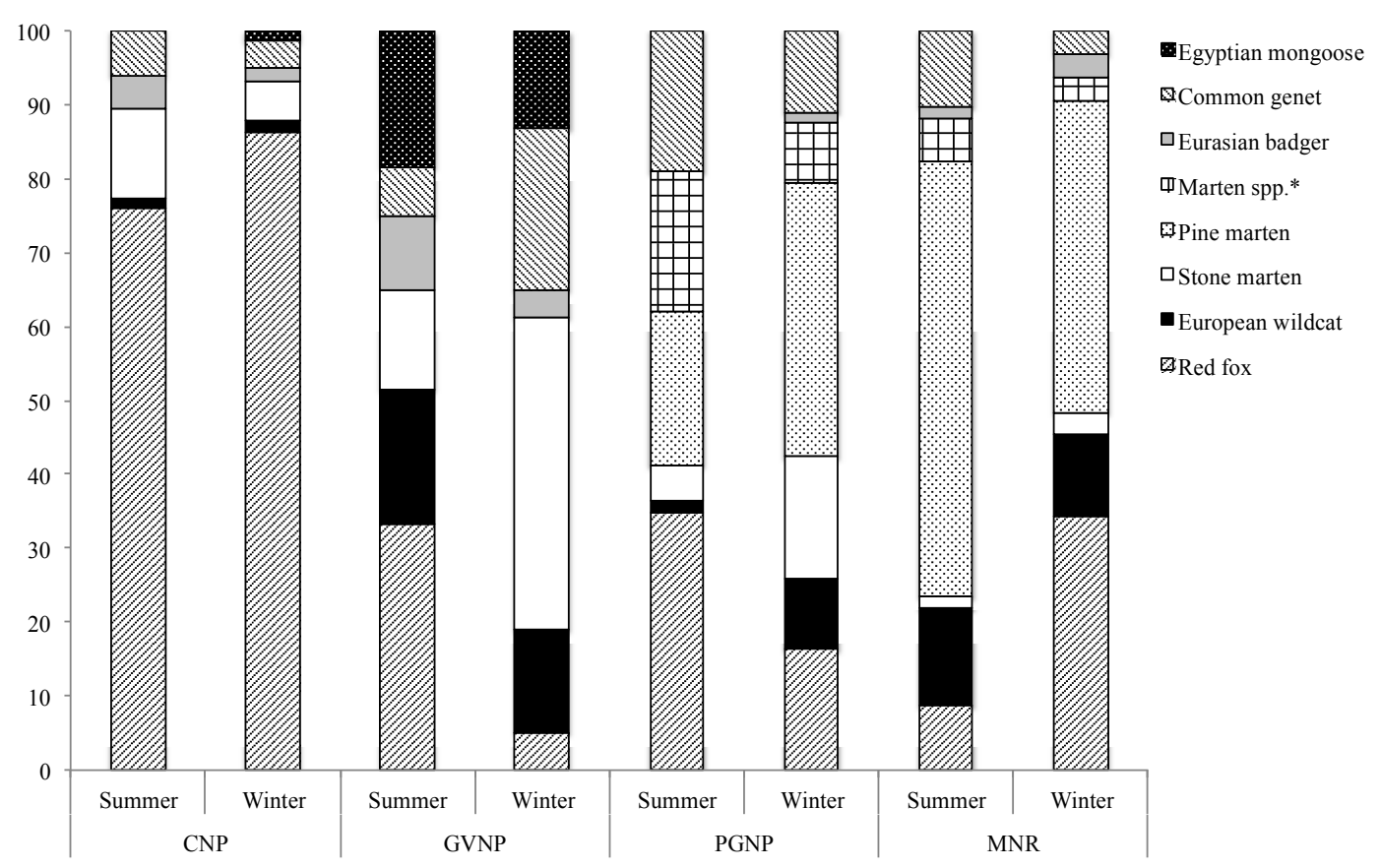

Figure 4 